\title{
Validation of CFD Capability for Supersonic Transport Analysis Using NEXST-1 Flight Test Results
}

\author{
Masaki Umeda*, Keizo Takenaka**, Keita Hatanaka**, \\ Daisuke Hirayama*, Wataru Yamazaki*, Kisa Matsushima*, and \\ Kazuhiro Nakahashi* \\ * Department of Aerospace Engineering, Tohoku University, Sendai, 980-8579 JAPAN \\ E-mail address : umeda@ad.mech.tohoku.ac.jp \\ ** Mitsubishi Heavy Industries, Ltd.
}

\begin{abstract}
CFD analyses of a flow field around supersonic transport, NEXST-1 are conducted. The CFD results are compared with flight test data. In this paper, $C_{D}$ and $C p$ discrepancies between them are mainly discussed with consideration of the effects of transition and local geometry change by protuberances of measuring instruments. As for the $C_{D}$ discrepancies, CFD results have more (4-9cts) profile drag, which could be the sum of spurious numerical error and turbulence model mismatch. As for the $\mathrm{Cp}$ discrepancies, $\mathrm{Cp}$ values at local points are definitely influenced by protuberances. Through the discussion, we also demonstrate how the CFD simulation can augment the validity of the flight test data.
\end{abstract}

\section{Introduction}

JAXA (Japan Aerospace Exploration Agency) developed a scaled, un-manned and non-powered experimental supersonic airplane (NEXST-1) to research next generation supersonic transport [1] As NEXST-1 design concepts for drag reduction, a cranked arrow planform and a warped camber, an area-ruled body and a supersonic natural laminar flow (NLF) wing [2,3] were employed. The aerodynamic shape was designed mostly by using CFD tools such as numerical simulations, numerical optimization and inverse problem design to achieve a high lift-to-drag ratio. This CFD design is one of the challenging subjects of NEXST project, because the traditional way of aircraft design is using wind-tunnel experiment.

The flight test of the NEXST-1 was conducted on Oct. 10th, 2005 at Woomera flight test range in Australia in order to verify and confirm the reliability of the above CFD aerodynamic design technologies. Fig. 1 shows flight path of NEXST-1 [4]. It obtained flight data at several angle of attacks and $\mathrm{Re}$ numbers including design point while gliding at Mach 2.0 [4,5]. Two kinds of aerodynamic measurements called $\alpha$-sweep and Re-sweep were conducted.

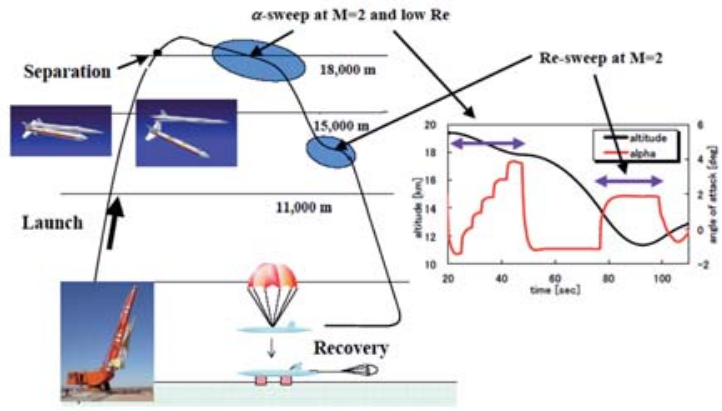

Fig.1 Flight path of NEXST-1 (from reference 4) 
JAXA's previous investigation [6] qualitatively confirmed that the design concepts are successfully realized by the CFD design. However, some quantitative discrepancies between flight test and the CFD results were observed. This fact indicated that further analysis and inspection were needed. Some principal problems which can be discussed on CFD capability are as follows;

Principal problems indicated by JAXA

1. $\mathbf{C}_{\mathbf{L}}$ characteristic; Why is there the difference of zero lift angle between flight test and CFD results? The difference is 0.15 deg.

2. $\mathbf{C}_{\mathbf{D}}$ characteristic; Why $\mathrm{C}_{\mathrm{D}_{-} \mathrm{CFD}}>\mathrm{C}_{\mathrm{D}_{-} \text {Flight }}$ (less than $6 \mathrm{cts}$ ), though no protuberances are attached on the computational geometry?

$\mathrm{C}_{\mathrm{D}_{-} \text {Flight }}$ was supposed to be larger because protuberances should cause extra drag force.

3. Cp distributions; Computational $\mathrm{Cp}$ values on lower surface of the wing and both surfaces of the body are slightly lower than the flight data.

4. Transition location pattern ; A criterion that 12.5 is the threshold value of $\mathrm{N}$ for $\mathrm{e}^{\mathrm{N}}$ transition prediction method is appropriate? Transition locations at the outer wing region were more forward than expected; why is it?

NEXST-1 configuration was designed by using CFD, not Wind Tunnel Test (WTT). The flight test was conducted in order to prove the reliability of developed CFD design technologies. So, we have to analyze small discrepancy between flight test and CFD results.

Therefore the objective of this study is to compare our CFD results with flight test and to analyze the causes of discrepancies between the two results. Especially, we treated $C_{D}$ characteristic and $\mathrm{Cp}$ distributions. We validated the CFD analysis methods by performing a lot of case studies of different computational conditions in terms of mesh types, mesh resolution, numerical algorithm and turbulence models. After that, we made consideration of transition effect on $C_{D}$ and geometry effect on $C_{D}$ and surface $C p$ distributions. Through the validation of these discrepancies, we try to demonstrate how the CFD simulation can augment the validity of flight test data.

The contents of this paper are as follows: In Section II, CFD solvers used in this study are shown. Computational geometries and computational cases are explained in Section III. One case of CFD results are compared with the other CFD results to investigate the effect of computational conditions such as mesh type, mesh resolution and so on. The CFD results are also compared with those of corresponding flight test in SectionIV. Finally conclusions and future works are shown in Section V.

\section{CFD solvers}

Two CFD solvers used in this study are presented in this section. One is JANET [7] developed by Mitsubishi Heavy Industries, Ltd. for structured mesh. It is mainly used for simple geometry problems such as wing-body design problem. A structured mesh method is generally said to be more accurate in computation. The other is TAS code [8-12] (Tohoku University Aerodynamic Simulation code) for unstructured mesh. It is mainly used for complex geometry problem. Both solvers are based on the 
Reynolds-averaged Navier-Stokes equations. The followings are the schemes and turbulence model which each solver employs.

\section{JANET}

- Convection terms; Roe's flux difference splitting with $3^{\text {rd }}$ order MUSCL

- Time integration; LUSGS ( the lower/upper symmetric Gauss- Sidel) implicit method [11]

- Turbulence model; Spalart-Allmaras / Baldwin-Lomax

\section{$\underline{\text { TAS code }}$}

- Convection terms; HLLEW (ㅂarten-Lax-van Leer-Einfeldt-Wada) approximate Riemann solver [8] with Green-Gauss/U-MUSCL [9,10] reconstruction method for numerical flux.

- Time integration; LUSGS implicit method

- Turbulence model; modified Spalart-Allmaras [12]

\section{Computational geometry and cases}

\section{Computational geometry}

We simulated two shapes. One is called aerodynamic shape shown in Fig. 2, which consists of a wing, a fuselage, a horizontal tail and a vertical tail, but neglects some small measuring instruments. The other shape is the exact flight shape with three protuberances, so it is very complicated. The flight shape is shown in Fig. 3. We simulated this complicated shape in order to research the influences of protuberances such as follows. Camera is attached to right wing lower surface. Air Data Sensor, hereinafter referred to as ADS, is attached to front body. Total Air Temperature probe, hereinafter referred to as TAT probe is attached to left wing lower surface. Both models are rigid $1 \mathrm{G}$ shape, because the effect of aeroelastic deformation on drag was found to be negligible by JAXA's previous investigation [13].

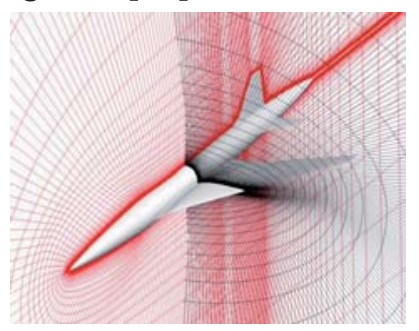

(a) Single Structured Grid

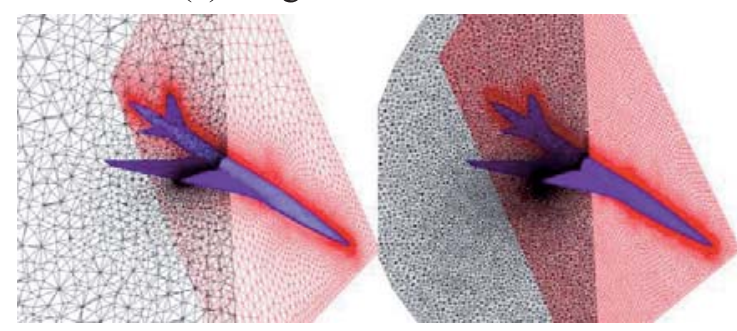

$\begin{array}{ll}\text { (b) Coarse unstructured grid } & \text { (c) Fine one }\end{array}$

Fig. 2 Grid distribution on the cross-flow sectional plane at $x=0.5 \mathrm{l}$ and the symmetrical plane of the aerodynamic shape ( $l$ :body length)

Aerodynamic shape grids are shown in Fig. 2. Single structured grid (a) for half model has $170 \times$ $161 \times 70=1,915,900$ points. Fig. 2 (b), (c) are unstructured grids for half model. Former is coarse grid, which contains $1,463,159$ nodes, 107,362 tetrahedra, 2,285,840 prisms, and 23,179 pyramids. The latter is fine grid with $7,575,826$ nodes, 13,101,244 tetrahedra, 10,277,679 prisms, and 100,641 pyramids. Unstructured grids in this study are generated by TAS-mesh [14-18]. Flight shape grid for full model, which is asymmetrical by the existence of protuberances, contains 12,810,994 nodes, 23,676,188 tetrahedra, 17,219,854 prisms, and 146,226 pyramids.

The resolution level of the used grid, Fig.2 (c) was checked. Fig.2 (c) is the same grid as that used by Team C. We thank that they provided it to us. The max and min of $y^{+}$of initial layer thickness are 
0.96 and 0.0005 , respectively. As for parameters of generating prismatic layers, the number of layers is 35 , the stretching factor is 1.2 . So that means there are 29 layers within laminar boundary. Therefore, the mesh resolution of boundary layer is enough for calculating viscous drag accurately.

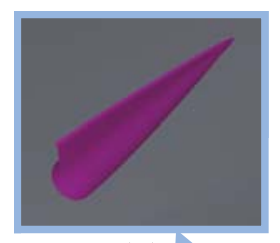

(b)

(a)

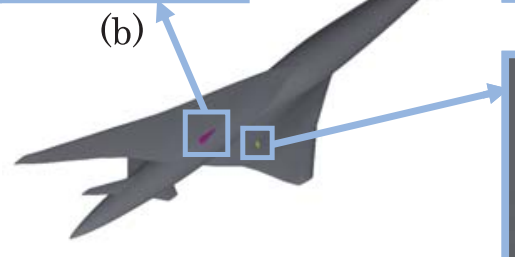

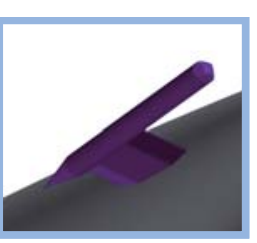

(c)

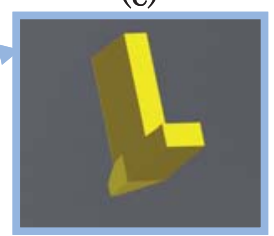

(d)

\section{Computational cases}

Table 1 shows specifications of computational cases. We simulated seven cases in order to research the various effects on the aerodynamic characteristics due to CFD technique itself and physical flow phenomena, described below.

Effects extracted by the comparisons;
A) Turbulence model effect; case1 with case2
B) Effect of Reconstruction of numerical flux; case 3 with case 4
C) Mesh type effect; case1 with case5
D) Mesh resolution effect; case3 with case5
E) Transition effect; case 5 with case6
F) Protuberance effect; case 5 with case 7

Fig. 3 Flight shape: (a) Perspective view of the airplane; (b) Close-up view of Camera; (c) Close-up view of ADS; (d) Close-up view of TAT probe

Table 1 Specifications of computational cases

(a) Aerodynamic shape

\begin{tabular}{|c|c|c|c|c|c|c|c|}
\hline Case & Tool & \multicolumn{2}{|c|}{ Grid nodes [million] } & Reconstruction & Turbulence model & Tranistion & Protuberances \\
\hline 1 & \multirow{2}{*}{$\begin{array}{c}\text { MHI } \\
\text { JANET }\end{array}$} & \multirow{2}{*}{ Structured } & \multirow{2}{*}{1.92} & \multirow{2}{*}{$\begin{array}{l}\text { 3rd order } \\
\text { MUSCL }\end{array}$} & Spalart-Allmaras & \multirow{5}{*}{$\begin{array}{c}\text { Fully } \\
\text { turbulent }\end{array}$} & \multirow{6}{*}{$x$} \\
\hline 2 & & & & & Baldwin-Lomax & & \\
\hline 3 & \multirow{4}{*}{ TAS } & \multirow{4}{*}{ Unstructured } & \multirow{2}{*}{1.46} & Green-Gauss & \multirow{4}{*}{ Spalart-Allmaras } & & \\
\hline 4 & & & & U-MUSCL & & & \\
\hline 5 & & & \multirow{2}{*}{7.57} & \multirow{2}{*}{ Green-Gauss } & & & \\
\hline 6 & & & & & & $\begin{array}{c}\text { Forced } \\
\text { Transition }\end{array}$ & \\
\hline
\end{tabular}

(b) Flight shape

\begin{tabular}{|c|c|c|c|c|c|c|c|}
\hline 7 & TAS & Unstructured & $\mathbf{1 2 . 8}$ & Green-Gauss & Spalart-Allmaras & $\begin{array}{c}\text { Fully } \\
\text { turbulent }\end{array}$ & 0 \\
\hline
\end{tabular}


Table 2 Free stream condition ( $\alpha$-sweep)

\begin{tabular}{|r|r|r|}
\hline \multicolumn{1}{|c|}{ Mach } & Rec [million] & AoA [deg] \\
\hline 2.0 & 12.71 & -1.516 \\
\hline 2.0 & 13.35 & -0.088 \\
\hline 2.0 & 14.23 & 0.767 \\
\hline 2.0 & 14.91 & 1.588 \\
\hline 2.0 & 15.51 & 2.540 \\
\hline 2.0 & 15.82 & 3.452 \\
\hline
\end{tabular}

In case6, transition location was determined by the results of flight test measurements and the transition effect was treated by the cut-off of the production term of the turbulence model in the laminar flow region.

Free stream conditions for calculations correspond to the $\alpha$-sweep mode (see Table 2). Rec means Reynolds number based on MAC length.

\section{Results and Discussion}

\section{Lift and Pitching Moment}

The lift and pitching moment characteristics are shown in Figs. 5 and 6. All CFD results agree well with flight test data. The difference, $\Delta \mathrm{C}_{\mathrm{L}}$ and $\Delta \mathrm{C}_{\mathrm{M}}$, is less than 0.005 , around the design $\mathrm{C}_{\mathrm{L}}$ condition the difference is less than $0.002(2 \%)$. Small discrepancies can be found in the slopes of the characteristic lines. Flight test results have smaller positive slope in lift characteristic, and smaller negative slope in pitching moment characteristic. These differences are thought to be due to aeroelastic wing deformation [13]. The effect of CFD analysis types, mesh resolution and turbulence model on $C_{L}$ and $C_{M}$ is found very small.

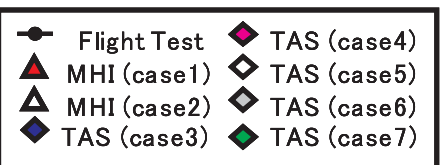

Fig. 4 Symbols of Figs. 7-9

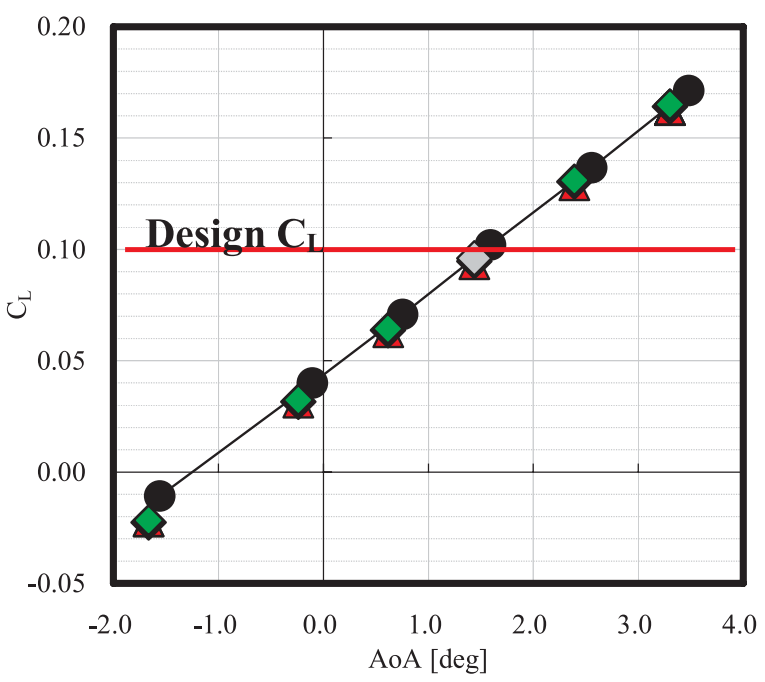

Fig. 5 Lift characteristic

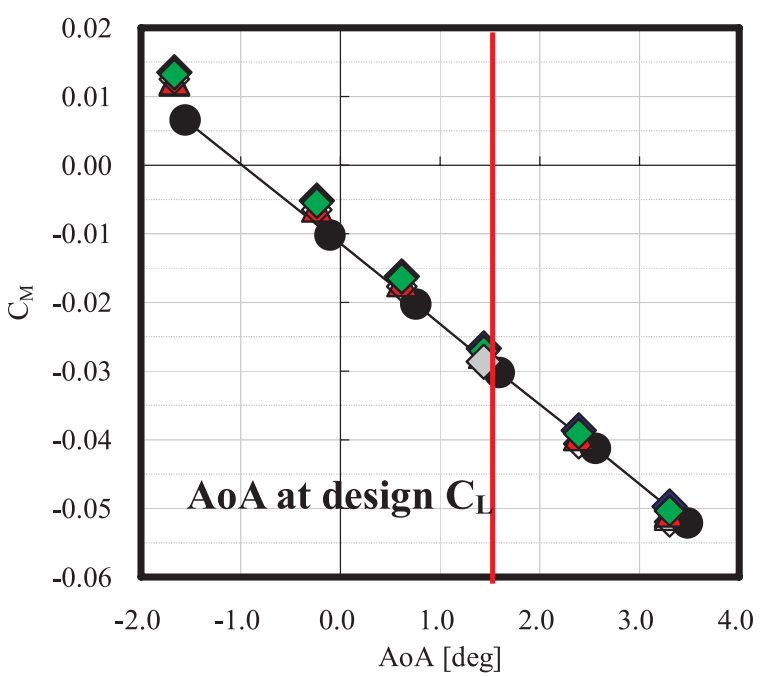

Fig. 6 Pitching Moment characteristic 


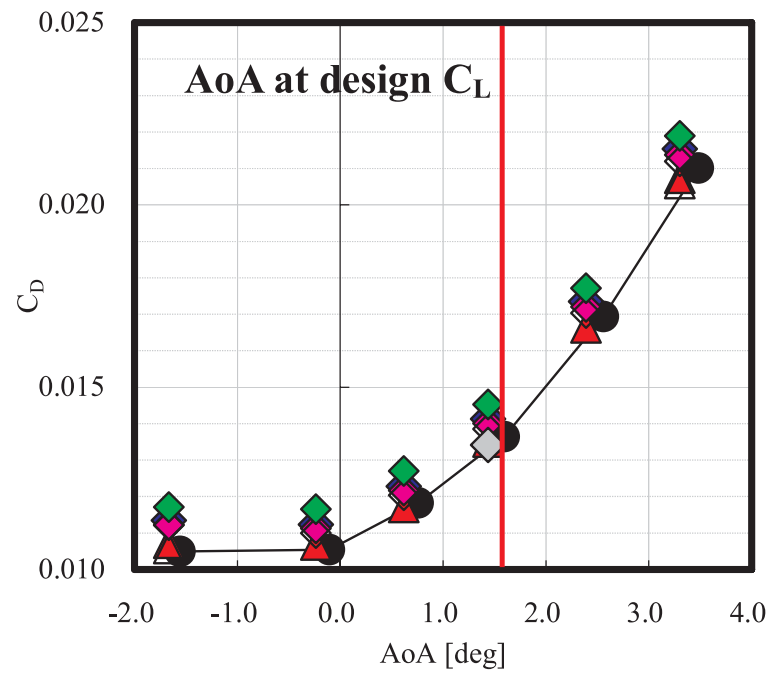

Fig. 7 Drag characteristic

\section{$\underline{\text { Drag }}$}

The drag characteristic is shown in Fig. 7. $\Delta C_{D}$ among the flight test data and CFD results is 5 to 9 counts. The differences due to the effect of each computational condition mentioned before are ;.
A) Turbulence effect;
1 count $\Delta \mathrm{C}_{\mathrm{D}}=$ case $2-$ case 1
B) Effect of Reconstruction of numerical flux;
1-2 counts
$\Delta \mathrm{C}_{\mathrm{D}}=$ case $3-$ case 4
C) Mesh type effect;
$\Delta \mathrm{C}_{\mathrm{D}}=$ case $5-$ case 1
D) Mesh resolution effect; $\quad$ 1-3 counts $\Delta \mathrm{C}_{\mathrm{D}}=$ case 3 - case 5
E) Transition effect; $\Delta \mathrm{C}_{\mathrm{D}}=$ case 5 - case 6
F) Protuberance effect;

\section{5-7 counts} $\Delta \mathrm{C}_{\mathrm{D}}=$ case $7-$ case 5

These effects A)-D) are shown in Fig. 8. It means that scatter in CD prediction among different CFD analysis types is less than 5 counts. This value could be error bar of CFD analysis types on supersonic flow.

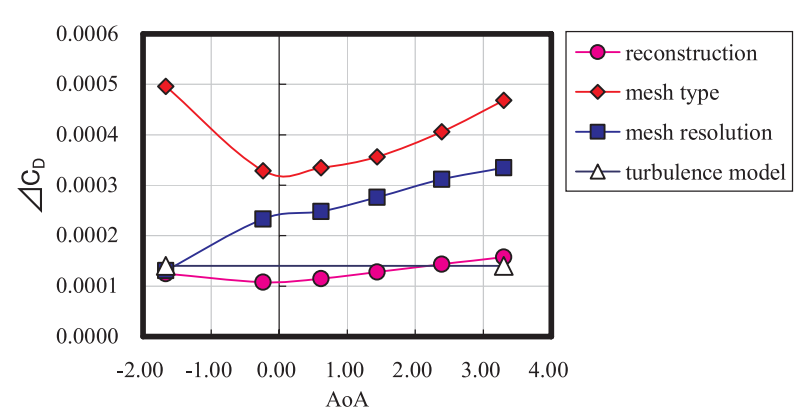

Fig. 8 Effects of CFD analysis types

\section{Drag Polar}

In this subsection, we diagnose the $C_{D}$ discrepancy between Flight test and CFD results. Drag polar curves of case1, 5, 7 and flight test are shown in Fig. 9. There is the $C_{D}$ discrepancy among them. The $C_{D}$ of flight test has the effects of protuberances and transition. However the computation of case1, 5 did take neither effect into account. The computation of case 7 considered only the protuberance effect. The proper corrections are applied to $C_{D}$ of those $C F D$ results in order to compare them on the equivalent condition as the flight data.

At first, correction of the effect of protuberances is applied to the results of case 1 and 5. This value is about +5 counts. It is estimated from JAXA WTT [19] and the results of the computational case study (see F) Protuberance effect in the previous section). $\Delta C_{D}$ of each protuberance from WTT is shown with that of CFD (case 7) in Fig. 10. We see from this figure that each $\Delta C_{D}$ of CFD (case7) agree very well with WTT. We assume that pressure drag is mainly influenced by protuberances. 


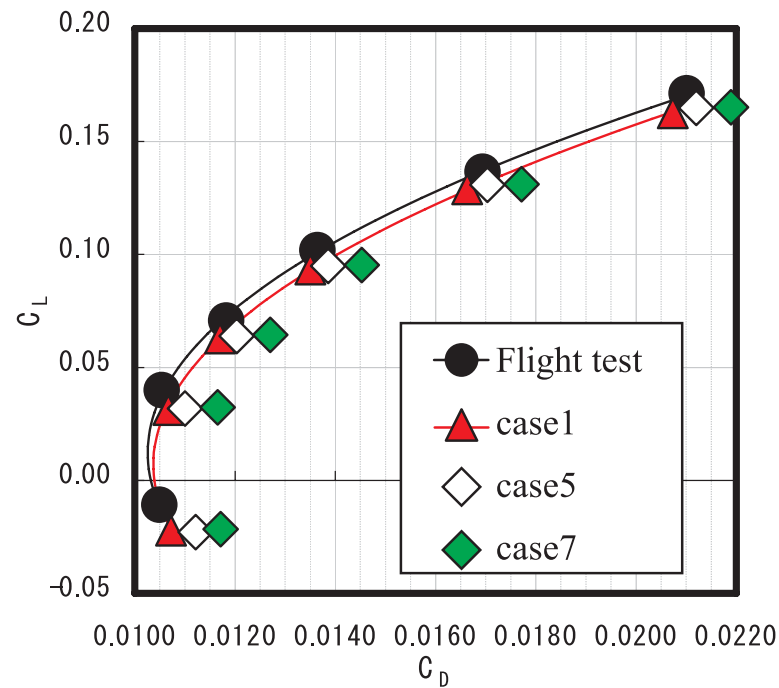

Fig. 9 Drag Polar before corrections

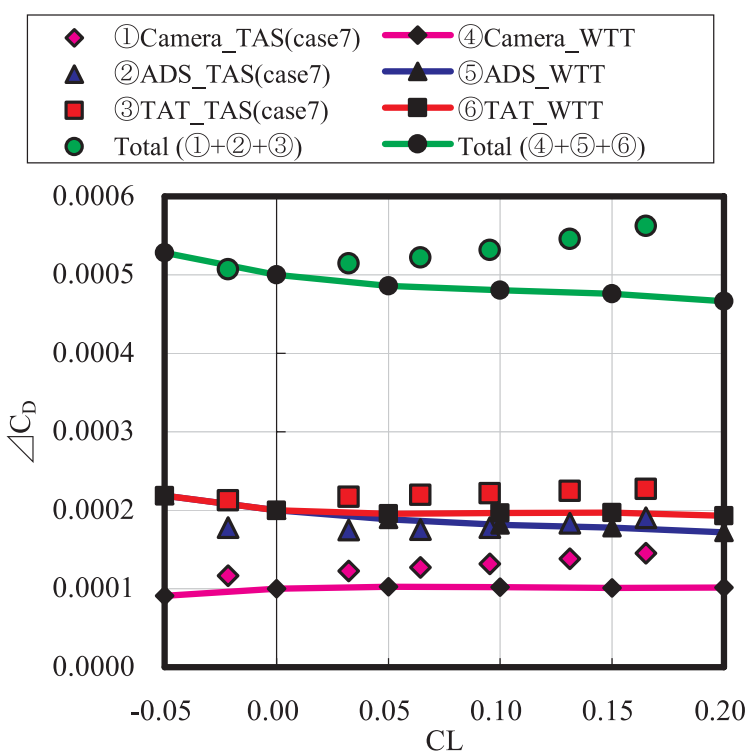

Fig. $10 \Delta \mathrm{C}_{\mathrm{D}}$ comparison protuberances between CFD and WTT

Next, correction of transition effect is applied. This value is -2 to -4 counts. It is estimated by Handbook method based on the theory of flat plate boundary layer [20] as follows.

$$
\begin{aligned}
& C_{D F}=C_{F}(\operatorname{Re}, M) \cdot \frac{S_{W E T}}{S} \\
& C_{F}(\operatorname{Re}, M)=C_{F L}(\operatorname{Re}) \cdot f(M)
\end{aligned}
$$

$$
\begin{aligned}
& \mathrm{C}_{\text {FL }}(\mathrm{Re})=\frac{0.455}{\left(\log _{10} \mathrm{Re}\right)^{2.58}} \\
& \mathrm{f}(\mathrm{M})=\left(1+0.15 \mathrm{M}^{2}\right)^{-0.58}
\end{aligned}
$$

,where $\mathrm{S}$ is reference area, $\mathrm{S}_{\mathrm{WET}}$ is wetted area of each component (wing, horizontal tail, vertical tail and body), $\mathrm{Re}$ is Reynolds number based on characteristic length of each component, and $\mathrm{M}$ is Mach number. Eq. (3) is from fully turbulent boundary layer of flat plate. Transition effect is estimated as the product of $\mathrm{C}_{\mathrm{DF}}$ (Eq. (1)) and the ratio of turbulent flow area (total area minus laminar flow area) to total area.

The accuracy of the handbook method and Navier-Stokes computations is confirmed by each other. Fig. 11 compares fully turbulent skin friction force by the handbook method with that by the N-S computation at design $C_{L}$. Both agree well with each other.

The laminar flow area is determined from the Hot Film measurement data [5] as is shown in Fig. 12. Then the ratio of turbulent area is calculated.

As illustrated in Fig. 13, transition effect of handbook method agrees well with CFD results of case 6 . The effect on body was negligible. NLF wing concept for drag reduction is particularly confirmed at design point.

Now, all cases have the effects of protuberances and transition. On the top of it, we artificially shift the CFD results to make them coincide with the flight test. Each offset value of case1, 5, 7 is respectively $-4,-8,-9$ counts. Drag polar curves with these corrections are shown in Fig. 14. All the drag polar curves are identical with each other, which means that lift dependent-wave and vortex drag of CFD computation agree very well with 
flight test, however, CFD results have more (4-9 counts) profile drag. We suggest that this profile drag could be the sum of turbulence modeling error and spurious numerical error if the flight test $C_{D}$ is completely correct.

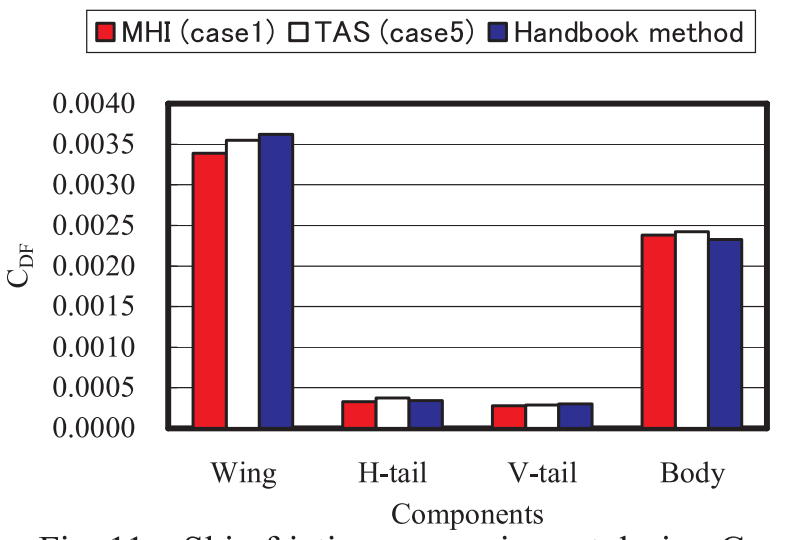

Fig. 11 Skin friction comparison at design $C_{L}$ (fully turbulent)

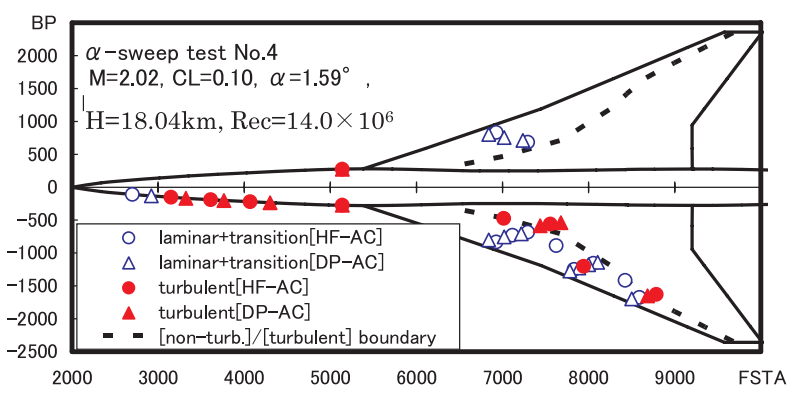

Fig. 12 Transition measurement results at a design point

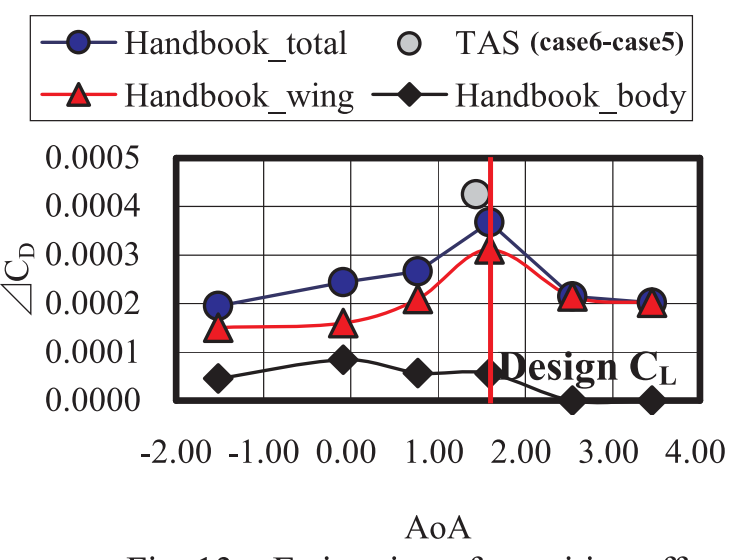

Fig. 13 Estimation of transition effect

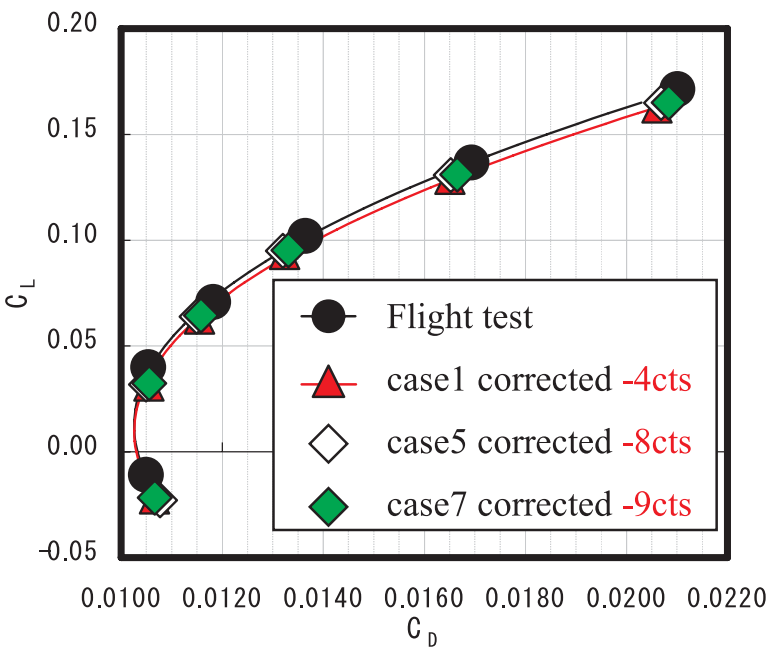

Fig. 14 Drag Polar after corrections

\section{$\underline{C_{P}} \underline{\text { distribution }}$}

Figs. 15(a) - 15(f) show chord-wise $C_{P}$ distributions at several span stations compared with those of the flight test results at the design point (AOA is $1.58^{\circ}$ ). At any span stations, CFD results on the upper surface are within the error bar 0.0115, however CFD results on the lower surface are slightly shifted to negative $C_{P}$.

At local points like $\mathrm{x} / \mathrm{L}=10,55$ [\%] on Fig. 15 (b), $\mathrm{x} / \mathrm{C}=80[\%]$ on Fig. 15 (e) and $\mathrm{x} / \mathrm{C}=80[\%]$ on Fig. 15 (f), flight test $\mathrm{Cp}$ value is obviously different from CFD results of aerodynamic shape (case 1, 5). When we see only the Cp distribution by the simulation of the aerodynamic shape, accuracy of flight test data at the local points might be dubious. But, CFD results of the flight shape with several protuberances definitely indicate that there is protuberance influence at the points. Therefore the flight shape computation qualitatively confirms the reliability of flight test data. That is one example for CFD to augment and support flight test data reliability. $C_{P}$ distribution contour maps corresponding to the protuberance influence are 
shown in Fig. 16. The compression and expansion waves from protuberances affect $C_{P}$ distributions.

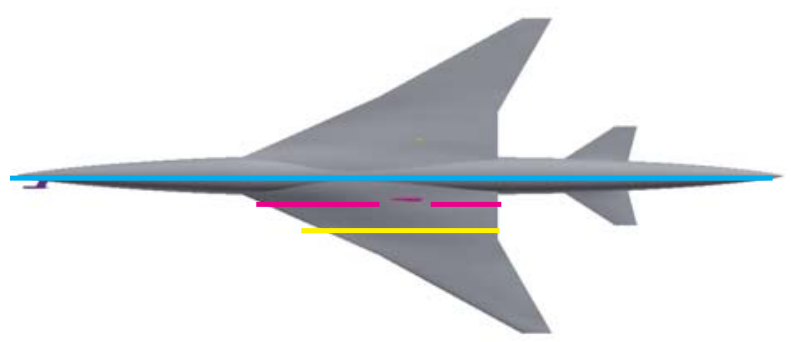

(a) Bottom view of the airplane

Flight (upper) - TAS (case5)
$\square$ Flight (lower) - TAS (case7)
- MHI (case1)
— Cross section of body and wing

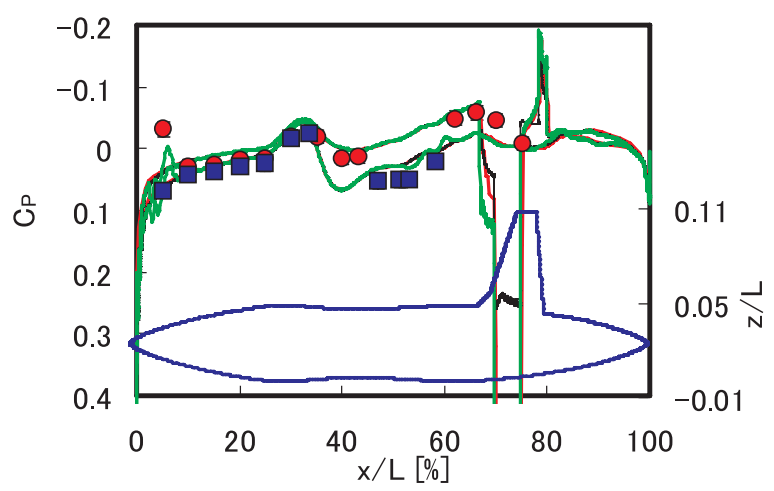

(b) $\mathrm{y} / \mathrm{S}=0.0$

(The span station is indicated as blue line in (a).)
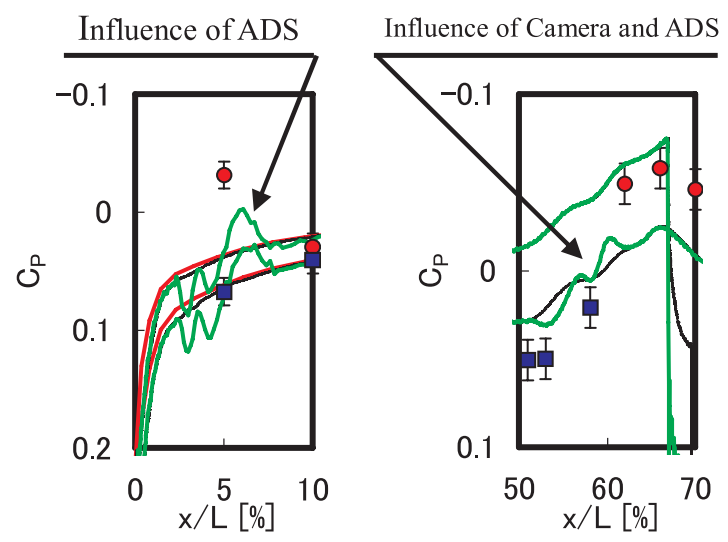

(c) near leading edge at $\mathrm{y} / \mathrm{S}=0.0$ (d) 0.6-0.75 chord

at $\mathrm{y} / \mathrm{S}=0.0$

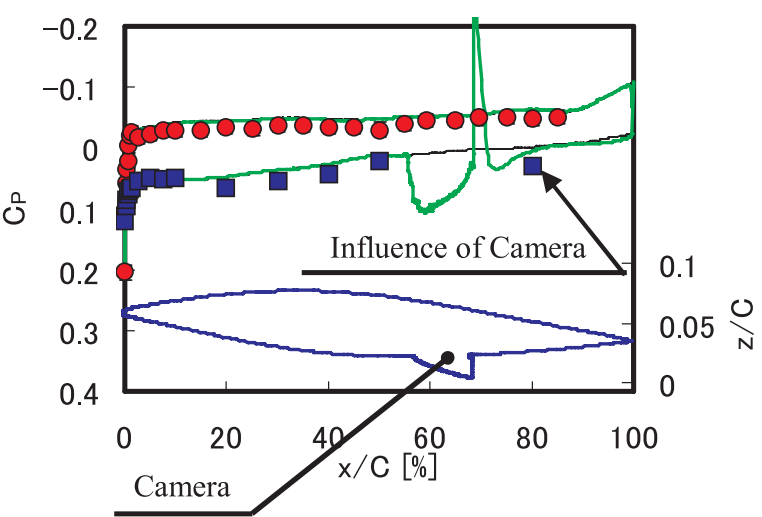

(e) $\mathrm{y} / \mathrm{S}=0.15$

(The span station is indicated as pink line in (a).)

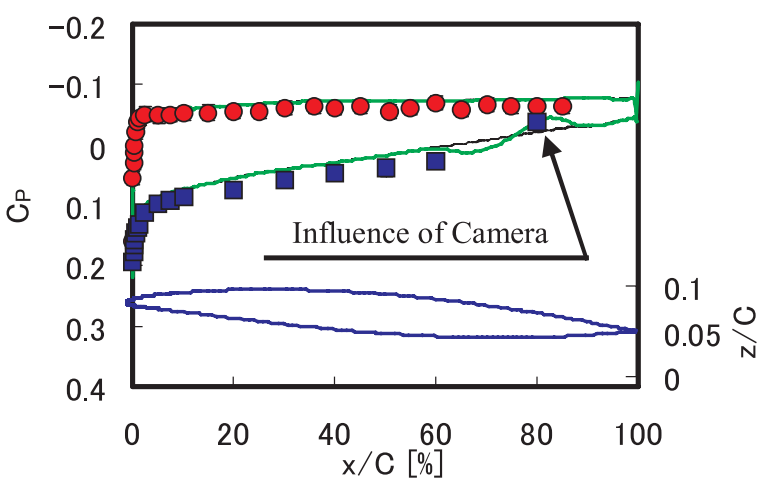

(f) $\mathrm{y} / \mathrm{S}=0.30$

(The span station is indicated as yellow line in (a).)

Fig. 15 Comparison of pressure distributions on the flight test with CFD at design point

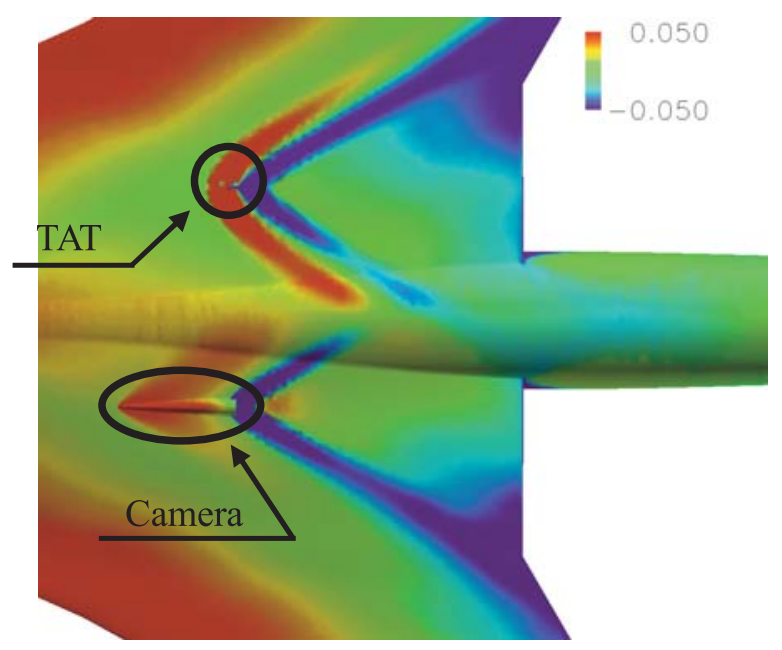

(a) Bottom view of wing surface 


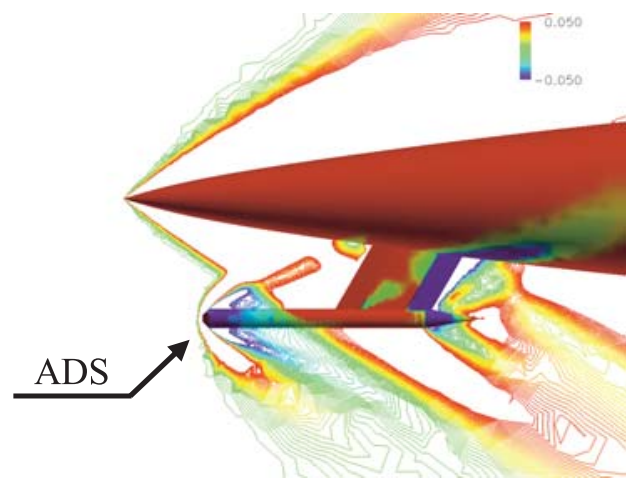

(b) Bottom view of ADS

Fig. $16 \mathrm{C}_{\mathrm{P}}$ distributions at design point on case 7

Furthermore, flight test $C_{P}$ distributions of the wing in Fig. 15 agree well with target $C_{P}$ data for the inverse design [3], which proves the validity of the inverse design of NEXT project.

\section{Conclusions and future work}

\section{Conclusions}

The validation of the CFD analysis methods with principal problems indicated by JAXA are conducted by comparing our CFD results with flight test data.

We validate our CFD analysis methods by considering a lot of case studies of different computational conditions in terms of mesh types, mesh resolution, numerical algorithm and turbulence models. From the case studies, the level of uncertainty among CFD simulations which is error bar on aerodynamic coefficients by CFD on supersonic flows is estimated. This value is 5 counts.

Then, the validation with the principal problems indicated by JAXA has been conducted.

1. $\mathbf{C}_{\mathbf{D}}$ characteristic ; Corrections are made on the CFD results, in the consideration of transition and protuberance effect. After correction, CFD results still have more (4-9cts) profile drag. This drag difference could be the sum of spurious numerical error and turbulence model mismatch.

2. Cp distributions; The detailed simulation using the complete NEXST-1 geometry of the flight shape reveals $\mathrm{Cp}$ values at several local points are definitely influenced by protuberances. That qualitatively confirms the validity of flight test data.

Through the above analyses, the validity of our CFD tools has been generally confirmed. We also have demonstrated that the CFD simulation has capability to augment the validity of the flight test data.

\section{Future work}

We are trying to apply advanced drag prediction methods to current CFD results. These methods can decompose total drag into physical drag components such as wave, profile, induced and spurious drag which is due to the effect of the numerical diffusion and error. The more accurate drag prediction can be realized by the elimination of the spurious component from the total drag. Moreover, as seen in Appendix, the drag decomposition into each component is also useful for drag analysis and drag reduction design. As said before, our drag decomposition uses CFD simulation results, which might be more realistic to flow physics. That technique for subsonic and transonic flow $\left(\mathrm{M}_{\infty}<\right.$ 1.0) has been developed and has given successful results [10]. For supersonic flows, we cannot simply apply the technique for the flow of $\mathrm{M}_{\infty}<1.0$, and extra different strategy is needed for the drag decomposition. 
We are currently working on them.

\section{Acknowledgement}

The flight test data shown in this paper was provided by JAXA. We sincerely thank Supersonic Transport Team, Aviation Program Group at JAXA. The present computation was performed using NEC-7c in Super-Computing System Information Synergy Center, Tohoku University. We sincerely thank all the staff for their helpful assistances.

\section{References}

[1] Ohnuki, T., Hirako, K., Sakata, K., "National Experimental Supersonic Transport Project,“ Proceedings of the $25^{\text {th }}$ International Congress of the Aeronautical Sciences, 2006

[2] Yoshida, K., Makino, Y., "Aerodynamic Design of Unmanned Scaled Supersonic Experimental Airplane in Japan", ECCOMAS 2004, Jyvaskyla, 24-28, 2004

[3] Matsuhima, K., Iwamiya, T., Nakahashi, K., "Wing design for supersonic transports using integral equation method," Engineering Analysis with Boundary Elements 28, 247-255, 2004

[4] Kwak, D., Yoshida, K., Ishikawa, H., Noguchi, M., "Flight Test Measurements of Surface Pressure on Unmanned Scaled Supersonic Experimental Airplane," AIAA Paper 2006-3483, June 2006

[5] Tokugawa, N., Yoshida, Y., "Transition Detection on Supersonic Natural Laminar Flow Wing in the Flight," AIAA Paper 2006-3165, June 2006

[6] Yoshida, K., "Outline of CFD Workshop on flight test results of NEXST-1 airplane," $4^{\text {th }}$ SST-CFD Workshop, JP-3, Tokyo, Sep. 2006
[7] Takenaka, K., Yamamoto, K., Takaki, R., "CFD Validation Study of NEXST-1 Near Mach 1, Proceedings of the $24^{\text {th }}$ International Congress of the Aeronautical Sciences," ICAS2004

[8] Sharov, D., Nakahashi, K., "Reordering of Hybrid Unstructured Grids for Lower-Upper Symmetric Gauss-Seidel Computations," AIAA Journal, Vol. 36, No.3, 1998, pp.484-486

[9] Burg, C. O. E., "Higher Order Variable Extrapolation for Unstructured Finite Volume RANS Flow Solvers," AIAA Paper 2005-4999, 2005

[10] Yamazaki, W., Matsushima, K., Nakahashi, K., "Unstructured Mesh Drag Prediction Based on Drag Decomposition," European Conference on Computational Fluid Dynamics, 2006

[11] Obayashi, S., Guruswamy, G. P., "Convergence Acceleration of an Aeroelastic Navier-Stokes Solver," AIAA Journal, Vol. 33, No.6 pp. 1134-1141, 1995

[12] Dacles-Mariani, J., Zilliac, G. G., Chow, J. S., Bradshaw, P., "Numerical/Experimental Study of a Wingtip Vortex in the Near Field," AIAA Journal, Vol. 33, No. 9, 1995, pp. 1561-1568.

[13] Kawakami, H., Kwak, D., Takatoya, T., Ishikawa, H., Kuroda, F., "Aeroerastic Analysis at the Flight Test of JAXA Supersonic Experimental Airplane," Proceeding of the $44^{\text {th }}$ Aircraft Symposium, 2006 (in Japanese)

[14] Sharov, D., Nakahashi, K., "A Boundary Recovery Algorithm for Delaunay Tetrahedral Meshing," Proceedings of $5^{\text {th }}$ International Conference on Numerical Grid Generation in Computational Field Simulations, 1996, pp. 229-238

[15] Ito, Y., Nakahashi, K., "Unstructured 
Hybrid Grid Generation Based on Isotropic Tetrahedral Grids," AIAA Paper 2002-0861, 2002

[16] Ito, Y., "Unstructured Mesh Generation for Viscous Flow Computations," Proceedings of the $11^{\text {th }}$ International Meshing Roundtable, Ithaca, NY, Sept. 2002, pp. 367-376

[17] Ito, Y., Nakahashi, K., "Direct Surface Triangulation Using Stereolithography Data," AIAA Journal, Vol. 40, No.3, pp. 490-496, 2002.

[18] Ito, Y., Nakahashi, K., "Surface Triangulation for Polygonal Models Based on CAD Data," International Journal for Numerical Methods in Fluids, Vol.39, Issue 1, pp.75-96, 2002

[19] Hirokaki, H., Kwak, D., Kawakami, H., Yoshida, K., "CFD Analysis on the Flight Test Data of Supersonic Experimental Airplane", Proceeding of the $44^{\text {th }}$ Aircraft Symposium, 2006 (in Japanese)

[20] Yoshida, K., "Fundamental Study on Aerodynamic Configuration of Second Generation SST," Japan Society for Aeronautical and Space Sciences Journal, Vol.42, No.486, pp.403-415, July, 1994 (in Japanese)

\section{Appendix: Handbook Method}

In this appendix, $C_{D}$ of NEXST-1 in a supersonic flow is estimated using the handbook method presented by Dr. Kenji Yoshida(JAXA) in Ref. 20. The method is as follows.

$$
\mathrm{C}_{\mathrm{D}}=\mathrm{C}_{\mathrm{DW}}+\mathrm{C}_{\mathrm{DL}}+\mathrm{C}_{\mathrm{DF}}
$$

where each drag component $C_{D W}, C_{D L}, C_{D F}$ is given by Eqs. (A2)-(A-14).

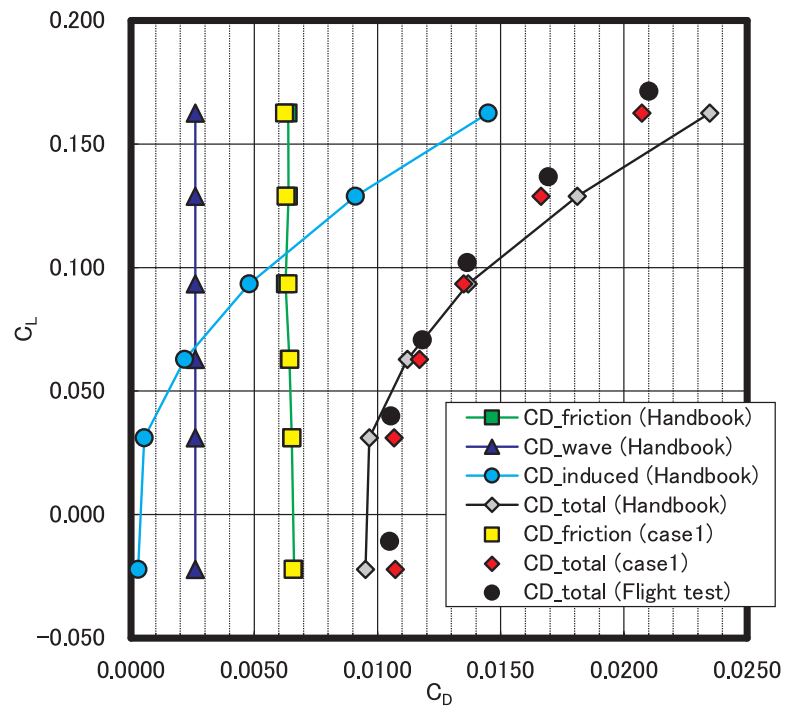

Fig. A-1 Comparison of CD

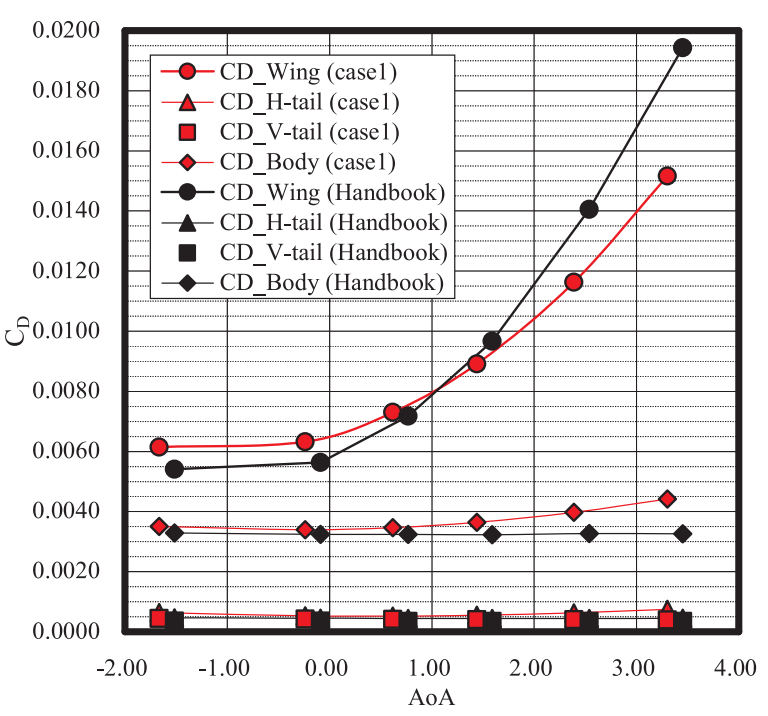

Fig. A-2 CD of each airplane component

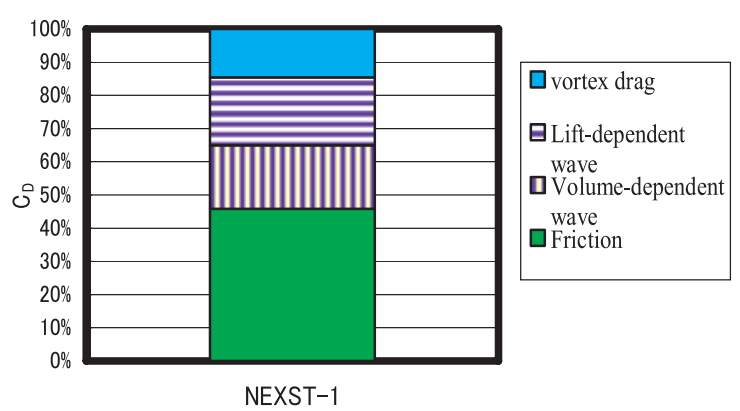

Fig. A-3 Distribution of drag components 


\section{For volume dependent wave drag of wings}

$\mathrm{CDW}=\frac{512}{\pi} \cdot\left(\tau \mathrm{p} \frac{\mathrm{s}}{l}\right) 2 \cdot \mathrm{K}_{0}\left(\beta \frac{\mathrm{s}}{l}\right) \cdot \frac{\mathrm{S}_{\mathrm{WET}} / 2}{\mathrm{~S}}$

$\mathrm{K}_{0}(\mathrm{x})=0.5114-0.4426 \log _{10 \mathrm{x}} \quad(0.12<\mathrm{x} \leq 1.0)$

$\tau=$ Volume $/ \mathrm{S}_{\text {wing }}^{3 / 2}$

$\mathrm{p}=\mathrm{S}_{\text {wing }} /(2 \mathrm{~s} l)$

$\beta=\sqrt{\left(M^{2}-1\right)}$

For volume dependent wave drag of slender bodies

$\mathrm{CDW}=\frac{4.69}{4}\left\{\frac{1}{\left(\frac{l_{\mathrm{N}}}{\mathrm{d}_{\max }}\right) 2}+\frac{1}{\left(\frac{l_{\mathrm{T}}}{\mathrm{d}_{\max }}\right) 2}\right\} \cdot \frac{\mathrm{S}_{\text {cross }}}{\mathrm{S}}$

$\mathrm{K}_{0}(\mathrm{x})=0.5114-0.4426 \log _{10 \mathrm{x}} \quad(0.12<\mathrm{x} \leq 1.0)$

\section{For induced drag due to lift}

$$
\begin{aligned}
& \mathrm{CDL}_{\mathrm{DL}}=\mathrm{CDWL}_{\mathrm{D}}+\mathrm{CDV}_{\mathrm{DV}} \\
& \mathrm{CDWL}=\frac{\mathrm{CL}^{2}}{2 \pi} \frac{\mathrm{p}}{(\mathrm{s} / l)^{2}} 2 \beta^{2} \cdot\left(\frac{\mathrm{s}}{l}\right)^{2} \cdot \mathrm{KW} \\
& \mathrm{CDV}=\frac{\mathrm{CL}^{2}}{2 \pi} \frac{\mathrm{p}}{(\mathrm{s} / l)} \cdot \mathrm{Kv} \quad\left(0.178<\beta \frac{\mathrm{s}}{l}\right) \\
& \mathrm{Kw}=\left(1+\frac{l}{\mathrm{p}}\right) \cdot \frac{\mathrm{fw}_{\mathrm{w}}(\beta \mathrm{s} / l)}{2 \beta^{2} \cdot\left(\frac{\mathrm{s}}{l}\right)^{2}} \\
& f W=\left\{\begin{array}{lc}
0.0 & , x \leq 0.178 \\
0.4935-0.2382 x+1.6306 x^{2}- & 0.86 x^{3} \\
+0.2232 x^{4}-0.0365 x^{5}-0.5 & , 0.178<x
\end{array}\right. \\
& \mathrm{Kv}=\frac{1}{2}\left(1+\frac{1}{\mathrm{p}}\right)
\end{aligned}
$$

where $\tau$ is volume parameter, $p$ is planform parameter, $l$ is maximum chord length, $\mathrm{s}$ is semi-span length, $\mathrm{d}_{\max }$ is maximum body diameter, $l_{\mathrm{N}}$ is the distance between nose and location at $\mathrm{d}_{\max }$ and $l_{\mathrm{T}}$ is the distance between back-end and location at $\mathrm{d}_{\max }$. Dr. Yoshida said each shape factor $\mathrm{K}\left(\mathrm{K}_{0}, \mathrm{~K}_{\mathrm{W}}, \mathrm{K}_{\mathrm{V}}\right)$ of these equations was determined from WTT of conventional SST (20).

A component $C_{D F}$ in Eq.(A1) is evaluated using Eqs (1)-(4) in Section IV .

The calculated $\mathrm{C}_{\mathrm{D}}$ by handbook method is compared with that by the flight test and CFD from several kind of aspect. Fig. A-1 shows $C_{D}$ and its drag components by the handbook method. Total $C_{D}$ of flight test, total and friction drag of CFD (case1) results are also presented. Roughly speaking, total $C_{D}$ of handbook agrees with that of flight test and CFD result. Especially, quantitative agreement is observed around the cruise condition $\left(\mathrm{C}_{\mathrm{L}}=0.1\right)$. Friction drag agrees very well between handbook and CFD. We think the reliability of the handbook method is validated in some extent However there is discrepancies in the $\mathrm{C}_{\mathrm{D} 0}$ (zero-lift $\mathrm{C}_{\mathrm{D}}$ ) and $\mathrm{C}_{\mathrm{D}}$ quantities when $C_{L}$ is higher than 0.1 . These are because that wave drag due to volume estimated by the handbook method is smaller than CFD prediction and the shape factor $\mathrm{K}$ of the handbook method is different from that for NEXST-1. In fact, $\mathrm{K}$ was determined from WTT of conventional SST (20). Shape factor $\mathrm{K}$ is determined for each geometrical component such as a main-wing, a horizontal-tail -wing, fuselage, etc.

To examine which shape factor is primarily different $C_{D}$ comparison in terms of each airplane 
component is made in Fig. A-2. There is obvious discrepancy in main wing's $C_{D}$. Thus, the shape factor of the main wing is the primary reason for the discrepancy. As for NEXST-1, CD rise per $\mathrm{AOA} / \mathrm{CL}$ increase is smaller than that estimated by the handbook method; in other words, NEXST-1 main wing has better aerodynamic characteristics $\left(\mathrm{C}_{D}\right.$ is more stable for $\mathrm{CL}_{\mathrm{L}}$ variation) than conventional SST. This implies that the wing design was done successfully.

Drag decomposition is conducted using the handbook method. The contribution of each drag component of physically different causes can be clearly seen in Fig. A-3. In the figure, the induced drag due to lift is further decomposed into wave drag and three-dimensional vortex drag. This information will be helpful when further drag reduction is performed. 